\title{
Local Effects of Acute Cellular Injury on Regional Myocardial Blood Flow
}

\author{
Frederick R. Cobb, Robert J. Bache, Frank Rivas, and \\ Joseph C. GreENFIELD, Jr. \\ From the Department of Medicine, Division of Cardiology, Veterans \\ Administration Hospital, Durham 27705, and Duke University Medical Center, \\ Durham, North Carolina 27710
}

\begin{abstract}
A B S T R A C T This study was designed to examine local effects of acute cellular injury on regional myocardial blood flow. Studies were carried out in awake dogs chronically prepared with indwelling catheters in the aorta and left atrium and an occluder on the left circumflex coronary artery. Regional myocardial blood flow was measured by using $7-10-\mu \mathrm{m}$ radioisotope-labeled microspheres after reestablishing inflow to a region subjected to a 2-h complete coronary occlusion. Microspheres were injected $15 \mathrm{~s}, 15 \mathrm{~min}, 4 \mathrm{~h}$, and 3 days after reperfusion to assess effects of cell injury at varying intervals after reperfusion. Effects of acute cellular injury on blood flow were assessed by determining the relationship between regional blood flow and the extent of subsequent cellular necrosis measured in multiple tissue samples, weight 1-2 g, from the entire ischemic zone. The extent of cellular necrosis was determined from histological sections of each tissue sample.

Prolonged ischemia effected local tissue responses which altered perfusion as a function of the interval after reperfusion and the subsequent extent of myocardial necrosis. Although the net response in each region immediately after reperfusion was vasodilation, the hyperemia in regions which subsequently suffered cellular necrosis was attenuated in direct proportion to the ex-
\end{abstract}

This study was presented in part at the 47th Scientific Sessions of the American Heart Association in Dallas, Tex., 18-21 November 1974.

Dr. Cobb is a Clinical Investigator, Veterans Administration Hospital, Durham, N. C. Dr. Bache is recipient of Research Career Development Award 1-K4-HL-00039 from the U. S. Public Health Service. Dr. Rivas is supported by the Veterans Administration Specialty Training Program in Cardiology, grant TR-273. Dr. Greenfield is recipient of Research Career Development Award 1-K3-HL-28112 from the U. S. Public Health Service.

Received for publication 25 August 1975 and in revised form 5 January 1976. tent of subsequent infarction. Blood flow to acutely injured regions remained equal to, or in excess of, flow to nonischemic regions $15 \mathrm{~min}$ after reperfusion, but at 4 $\mathrm{h}$ and 3 days after reperfusion, flow was significantly decreased in regions with greater than $50 \%$ infarction.

Thus, these data indicate that prolonged ischemia initiates tissue responses which progressively reduce myocardial perfusion after reperfusion. These effects on tissue perfusion may result from normal responses to irreversible injury and (or) abnormal responses to reversible and thus, potentially alterable, ischemic injury.

\section{INTRODUCTION}

Several previous studies have indicated that prolonged myocardial ischemia may initiate local responses within the zone of ischemia which may reduce perfusion of the myocardium (1-5). Several investigators have concluded that local tissue responses to prolonged ischemia may play a direct and important role in determining the extent of subsequent cellular necrosis (1-3). The precise relationship between the extent of acute cellular injury and alteration in tissue perfusion has not been defined.

The objective of the present study was to examine local effects of acute cellular injury on regional myocardial blood flow. Regional myocardial blood flow was measured after reestablishing inflow to a region subjected to prolonged ischemia sufficient to initiate acute myocardial infarction. Effects of acute cellular injury on blood flow were assessed by determining the relationship between regional blood flow and the extent of subsequent myocardial infarction. To evaluate local effects of cellular injury at varying intervals after reperfusion, blood flow was measured $15 \mathrm{~s}, 15 \mathrm{~min}, 4 \mathrm{~h}$, and 3 days after reperfusion. The study was performed in awake chronically prepared animals to avoid the vari-

The Journal of Clinical Investigation Volume 57 May 1976 1359-1368 
ables introduced by general anesthesia and acute surgical trauma.

\section{METHODS}

Studies were performed in 22 mongrel dogs weighing 23-33 $\mathrm{kg}$. The dogs were anesthetized with thiamylal sodium (30$40 \mathrm{mg} / \mathrm{kg}$, i.v.) and underwent a left thoracotomy via the fourth intercostal space. The proximal $1 \mathrm{~cm}$ of the left circumflex coronary artery was dissected free and a pneumatic cuff occluder constructed in this laboratory of polyvinyl chloride tubing, $3 \mathrm{~mm} O D$, was placed around the vessel. Polyvinyl chloride catheters, $3 \mathrm{~mm}$ OD, were filled with heparin and inserted into the left atrial cavity via the atrial appendage and the aortic root via the left internal thoracic artery. The catheters and snares were stabilized and the ends were tunneled to a subcutaneous pouch at the base of the neck, so that they could be exteriorized by a $1-\mathrm{cm}$ skin incision before study.

Studies were performed 7-10 days after the surgical procedure. During the recovery period, the animals were checked frequently to assure that they were free of infection and anemia. The mean hematocrit at the time of study was 44 range $38-55 \%$. During the recovery period, the animals became accustomed to the laboratory environment and were trained to lie quietly on a laboratory table. The morning before the study, the catheters and snares were exteriorized from the subcutaneous pouch using lidocaine infiltration anesthesia. Studies were performed with animals lying on their right side and loosely restrained. The arterial and left atrial catheters were attached to pressure transducers zeroed at the mid-chest level (model P23Db, Statham Instruments Div., Gould Inc., Oxnard, Calif.). A lead III standard electrocardiogram was recorded. Phasic and mean hemodynamic and electrocardiographic signals were recorded continuously on a direct-writing oscillographic system (model 8800, Hewlett-Packard Co., Palo Alto, Calif.). After all recording instruments were connected, the laboratory lights were dimmed and all noise and activity minimized. A minimum of 45-60 min was allowed for each animal to adjust to quiet laboratory conditions.

To assure proper function of the coronary occluder, electrocardiographic and hemodynamic responses to a 45-60-s complete occlusion were observed. Proper function of the pneumatic occluder was verified by absence of abnormal $Q$ waves before occlusion, elevation of S-T segment, and an increase in heart rate and left atrial pressure within $30 \mathrm{~s}$ after complete occlusion, and returned to preocclusion values of each parameter within approximately $15 \mathrm{~s}$ after release of the occlusion. If the above responses were not observed, the animals were not included in the study. Complete coronary occlusion was then performed over a 15-min interval by gradually increasing the pressure in the occluder tubing. Complete occlusion was maintained for $2 \mathrm{~h}$. Blood flow was then reestablished to the ischemic area by completely deflating the occluder. Lidocaine, $2 \mathrm{mg} / \mathrm{kg}$, was administered intravenously before the occlusion and at 15-min intervals for $1 \mathrm{~h}$ after occlusion to reduce early arrhythmias. No antiarrhythmic agents were administered after the $1 \mathrm{st} \mathrm{h}$. Morphine sulfate, $10 \mathrm{mg}$, was injected intravenously as the snare was inflated to minimize any discomfort resulting from the coronary occlusion. Using this procedure, four dogs developed ventricular fibrillation after the occlusion and were excluded from the study.

Measurements of myocardial blood flow were made by serial injections of carbonized microspheres, $7-10 \mu \mathrm{m}$ in diameter, labeled with gamma-emitting nuclides ${ }^{51} \mathrm{Cr},{ }^{141} \mathrm{Ce}$,
${ }^{85} \mathrm{Sr}$, and ${ }^{46} \mathrm{Sc}$. The microspheres were obtained as $1 \mathrm{mCi}$ of each nuclide in $10 \mathrm{ml}$ of dextran and $0.05 \%$ polysorbate80 (3M Co., St. Paul, Minn.). The stock solution was diluted in $10 \%$ dextran so that each milliliter, the volume injected, contained approximately 3 million microspheres. Before injection the microspheres were thoroughly mixed by alternate agitation for at least $15 \mathrm{~min}$ in an ultrasonic bath (model DA0950, 3M Co.) and vortex agitator (Scientific Industries, Inc., Queens Village, N. Y.). Complete dispersion was verified by microscopic examination of a drop of the suspension. $1 \mathrm{ml}$ of the microsphere suspension was then injected into the left atrium over a 10-15-s interval via the previously implanted left atrial catheter and flushed in with $5-10 \mathrm{ml}$ of isotonic saline. Beginning simultaneously with the microsphere injection and continuing for $90 \mathrm{~s}$, a reference blood sample was collected from the aorta at a constant flow rate of $18 \mathrm{ml} / \mathrm{min}$ using a withdrawal pump (model 1210, Harvard Apparatus Co., Inc., Millis, Mass.). Serial injection of this quantity of microspheres resulted in no changes in heart rate during the injection or in arterial or left atrial pressure measurements made immediately before and after the collection of the reference blood sample.

Using this procedure, myocardial blood flow was measured $10 \mathrm{~s}, 15 \mathrm{~min}, 4 \mathrm{~h}$, and 3 days after release of the $2-\mathrm{h}$ occlusion. 6 days after the initial study the animals were anesthetized with thiamylal sodium and the hearts fibrillated with concentrated potassium chloride. The hearts were removed and placed in $10 \%$ buffered formalin for 3-4 days to facilitate sectioning. The atrium, right ventricle, aorta, pericardial fat, and large epicardial vessels were dissected from the left ventricle and discarded. The mean left ventricular weight was $106 \pm 7 \mathrm{~g}(\mathrm{SE})$. The left ventricle was sectioned into four transverse sections of approximately equal thickness (Fig. 1). Rings 2 and 3 were divided into six regions: anterior, septal, posterior, posterior papillary, lateral, and anterior papillary. Ring 1 was divided into two anterior and two posterior regions and lateral and septal regions. Ring 4 was divided into anterior, septal, posterior, and lateral regions. Each circumferential region in rings 1, 2, and 3 was then divided into four equal transmural layers of approximately equal thickness, sample size 1-2 g. Since the ventricular wall is thinner, ring 4 was divided into equal inner and outer layers. $10 \%$ buffered formalin was added to the vials to preserve the tissue for histological sections after measurement of the tissue radioactivity.

The radioactivity in each myocardial sample and reference blood sample was determined in a gamma spectrometer, using window settings selected to correspond to the peak energies of each radioactive nuclide. Radioactivity was corrected for overlapping radioactivity of the accompanying isotope using a digital computer. Blood flow to each area of myocardium in milliliters per minute was calculated using the formula

$$
Q_{m}=Q_{r} \cdot C_{m} / C_{r}, \ldots \ldots \ldots \ldots \ldots
$$

where $Q_{m}=$ myocardial blood flow (milliliters per minute), $Q_{r}=$ reference flow (milliliters per minute), $C_{m}=$ counts per minute in myocardial samples, and $C_{r}=$ counts per minute in reference flow samples. Myocardial flow in milliliters per minute was divided by sample weight and expressed as milliliters per minute per gram.

After measurement of tissue radioactivity, the segments were prepared for histological sectioning by recombining the segments from each circumferential region in the precut transmural sequence (Fig. 2). At least two histological sections were obtained at different depths from each tissue block containing the four transmural sections. The sections 

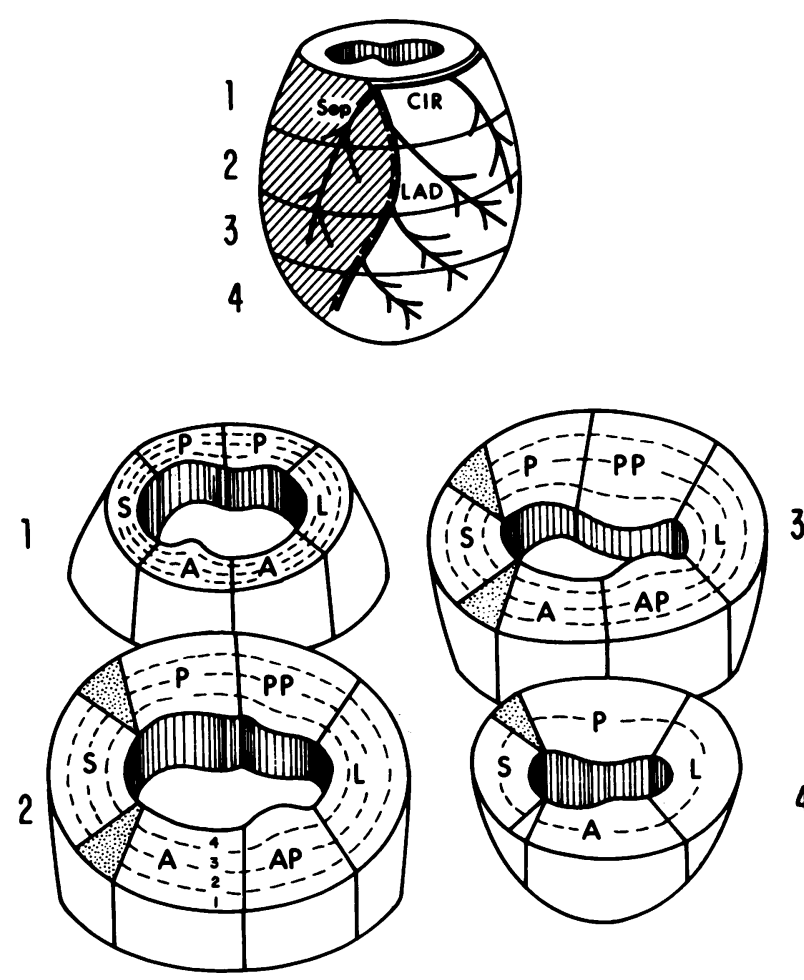

FIgURE 1 This schematic diagram illustrates the technique for sectioning the left ventricle. The atrial tissue and right ventricle were removed as indicated by the stippled and lined area. The left ventricle was sectioned into four transverse rings. Each ring was sectioned into circumferential regions, i.e., anterior (A), septal (S), posterior (P), posterior papillary $(P P)$, lateral $(L)$, and anterior papillary (AP). Each circumferential region in rings 1,2 , and 3 was divided into four equal transmural layers. Regions in ring 4 were divided into equal epicardial and endocardial layers.

were stained with hematoxylin and eosin. Myocardial infarction was defined as complete or partial cellular dissolution, inflammatory cell infiltrate, and loss of normal cellular architecture. The percentage of infarcted myocardium in each small myocardial sample was determined using grid marks which subdivided each tissue sample into equal regions. Each subdivided region was encompassed in a $\times 10$ power microscopic field. If the percentage of infarcted myocardium in the two histological sections of a small myocardial sample differed by more than $10 \%$, additional sections were obtained. Thus, blood flow and the extent of myocardial infarction were determined in multiple small tissue samples of the entire region subjected to ischemia.

A separate group of eight animals was prepared with chronic indwelling catheters and snares as described in the previous section. The blood flow response after transient ischemic stimulation of the normal coronary vasculature was measured by injecting microspheres over a $10-15-\mathrm{s}$ interval, beginning $10 \mathrm{~s}$ after the release of a 60 -s complete occlusion of the left circumflex coronary artery. Studies performed in this laboratory using awake dogs with chronically implanted electromagnetic flow probes have demonstrated that a 60 -s complete occlusion produces a reactive hyperemic response, characterized by a sustained maximum

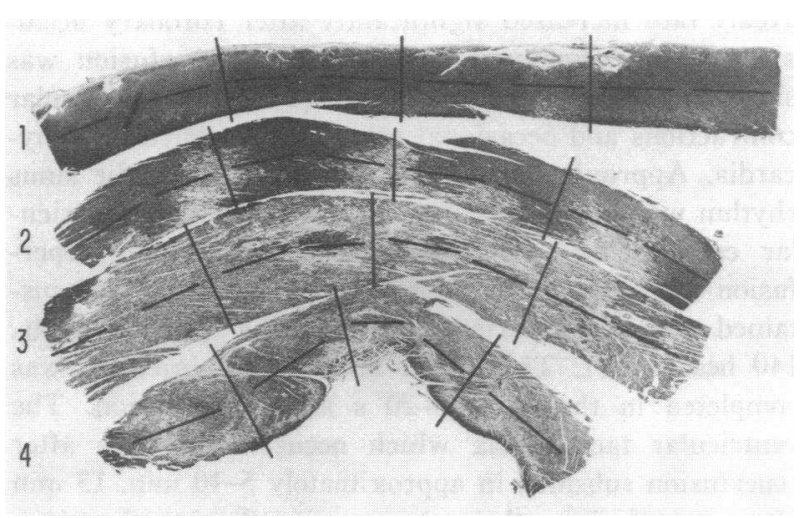

Figure 2 Histological section of myocardial samples from the posterior papillary muscle region of one ring. 1 is the outer epicardial and 4 the inner endocardial layer, respectively. The vertical and horizontal grid marks divide the samples into 25 and $12.5 \%$ sections, respectively. The extent of infarction was 2,30,91, and $100 \%$ in sections $1,2,3$, and 4, respectively. Magnification approximately $6.5 \times$ actual histological section.

increase in blood flow, lasting $30-45 \mathrm{~s}$ followed by gradual return to basal flow measurements. These animals were sacrificed after the blood flow measurement and were not subjected to acute infarction. Tissue samples and blood flow measurements were performed as described in the previous section.

Student's $t$ test for paired data was used to compare sequential changes in flow. Student's $t$ test for nonpaired data was used to compare flow in regions subjected to prolonged ischemia to flow in regions not subjected to ischemia.

\section{RESULTS}

Mean heart rate and mean arterial and left atrial pressure before and at intervals in 10 dogs after left circumflex coronary artery occlusion are tabulated in Table I.

TABLE I

Hemodynamic Measurements

\begin{tabular}{lccccc}
\hline & $\begin{array}{c}\text { Before } \\
\text { occlusion } \\
\text { control }\end{array}$ & \multicolumn{4}{c}{ Intervals after release of 2-h occlusion } \\
\cline { 3 - 6 } & & $15 \mathrm{~s}$ & $15 \mathrm{~min}$ & $4 \mathrm{~h}$ & 3 days \\
\hline HR, beats/min & 80 & 99 & 87 & 125 & 85 \\
SEM & \pm 5 & \pm 7 & \pm 4 & \pm 11 & \pm 7 \\
$P$ & & 0.03 & $\mathrm{NS}$ & 0.006 & $\mathrm{NS}$ \\
AP, $m$ m $H g$ & 97 & 104 & 92 & 95 & 99 \\
SEM & \pm 2 & \pm 4 & \pm 5 & \pm 2 & \pm 3 \\
$P$ & & NS & NS & NS & NS \\
LAP, $m$ m $H g$ & 6 & 11 & 10 & 8 & 8 \\
SEM & \pm 1 & \pm 1 & \pm 2 & \pm 3 & \pm 2 \\
$P$ & & 0.002 & NS & NS & NS \\
\hline
\end{tabular}

Measurements of heart rate (HR), mean arterial pressure (AP), and mean left atrial pressure (LAP), before left circumflex coronary artery occlusion and at intervals after release of a 2 -h complete occlusion. $P$ values compare the values to corresponding control measurements before occlusion. NS, $P>0.05$.

Myocardial Infarction and Blood Flow 
Heart rate increased significantly after coronary occlusion. The predominant rhythm before reperfusion was sinus tachycardia with occasional premature ventricular contractions and occasional periods of ventricular tachycardia. Approximately $20 \mathrm{~s}$ after reperfusion, the sinus rhythm was interrupted by frequent premature ventricular contractions. Approximately $30-45$ s after reperfusion the frequent premature contractions initiated sustained runs of ventricular tachycardia (average rate, 140 beats $/ \mathrm{min}$ ). The initial microsphere injection was completed in the first $15-20 \mathrm{~s}$ after reperfusion. The ventricular tachycardia which occurred $30-45$ s after reperfusion subsided in approximately 5-10 $\mathrm{min}$. $15 \mathrm{~min}$ after reperfusion, the rate was predominantly sinus rhythm with occasional or frequent premature ventricular contractions. $4 \mathrm{~h}$ after reperfusion the mean heart rate was $125 \pm 11$ beats/min, and the rhythm was predominantly ventricular tachycardia in eight dogs. 3 days after reperfusion the heart rate was sinus rhythm. However, occasional premature ventricular contractions were present in two dogs 3 days after reperfusion. Although arterial pressure frequently increased 5-10 $\mathrm{mm}$ $\mathrm{Hg}$ after complete occlusion, mean arterial pressure at the time blood flow measurements were made was not significantly different from control values. Mean left atrial pressure increased after coronary occlusion and remained significantly increased $15 \mathrm{~s}$ after reperfusion. The slightly higher values for left atrial pressure $15 \mathrm{~min}$, $4 \mathrm{~h}$, and 3 days after reperfusion did not achieve statistical significance.
The myocardial blood flow response in four transmural layers from the posterior, posterior papillary, and lateral regions of ring 2 in one dog at intervals after reperfusion are illustrated in Fig. 3. The percentage values indicate the amount of histologically determined myocardial infarction in each sample. Similar measurements were made in left ventricular samples from rings 1-4 in each dog. Since flow values in the same infarct ranges in different transmural layers were comparable, samples from all layers in each dog were then grouped according to the percentage of infarcted myocardium in ranges of $0-5,6-25,26-50,51-75,76-90$, and $91-100 \%$, and an average blood flow for each infarct range was determined. In a given dog, several samples often contributed to the average blood flow value in a given infarct range. The averages of similar blood flow measurements obtained in 10 dogs at intervals after reperfusion are tabulated in Table II. Flow values were not obtained in two animals at 3 days. Fig. 4 graphs the blood flow data from these 10 dogs, expressed as the ratios of blood flow in infarcted samples to blood flow in comparable transmural layers from the anterior wall. Samples containing $0-5$ and $6-25 \%$ of infarcted myocardium (Table II) were combined in Fig. 3, since blood flow measurements were not significantly different within this infarct range.

Blood flow to the anterior or control region was comparable $15 \mathrm{~s}, 15 \mathrm{~min}$, and $4 \mathrm{~h}$ after reperfusion. 3 days after reperfusion, anterior region blood flow had decreased to $0.86 \pm 0.01 \mathrm{ml} / \mathrm{min}$ per $\mathrm{g}$, a value com-

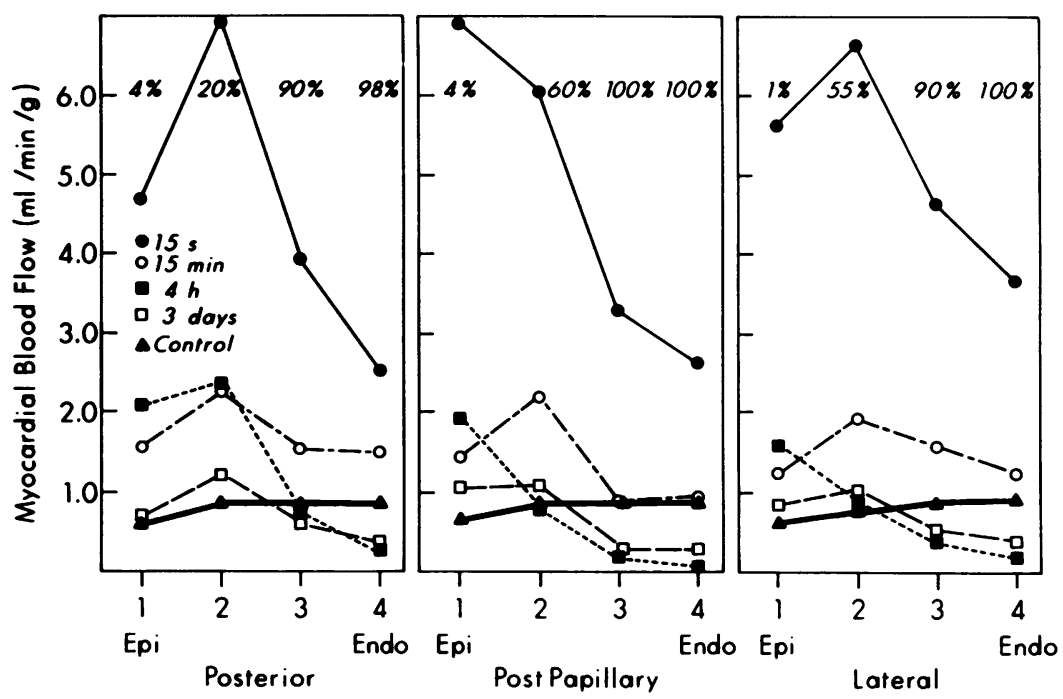

Figure 3 Myocardial blood flow in milliliters per minute per gram in transmural layers 1-4 in the posterior, posterior papillary, and lateral regions $15 \mathrm{~s}, 15 \mathrm{~min}, 4 \mathrm{~h}$, and 3 days after release of a 2-h circumflex occlusion. Control represents transmural blood flow in the anterior region 3 days after acute infarction. The percent values indicate the amount of infarcted myocardium in each sample. 
TABLE II

Relationship between Infarcted Myocardium and Blood Flow

\begin{tabular}{|c|c|c|c|c|c|c|c|}
\hline \multirow{2}{*}{$\begin{array}{l}\text { Time after } \\
\text { release of } \\
\text { occlusion }\end{array}$} & \multirow{2}{*}{$\begin{array}{c}\text { Anterior region } \\
0\end{array}$} & \multicolumn{6}{|c|}{ Left circumflex coronary artery region* } \\
\hline & & $0-5 \%$ & $6-25 \%$ & $26-50 \%$ & $51-75 \%$ & 76-90\% & $91-100 \%$ \\
\hline \multicolumn{8}{|l|}{$15 \mathrm{~s}$} \\
\hline $\begin{array}{l}1 \mathrm{SEM} \\
P\end{array}$ & $1.02 \pm 0.10$ & $\begin{array}{c}4.53 \pm 0.43 \\
<0.01\end{array}$ & $\begin{array}{c}4.97 \pm 0.58 \\
<0.01\end{array}$ & $\begin{array}{c}3.53 \pm 0.44 \\
<0.01\end{array}$ & $\begin{array}{c}3.53 \pm 0.53 \\
<0.01\end{array}$ & $\begin{array}{l}2.70 \pm 0.32 \\
<0.01\end{array}$ & $\begin{array}{c}1.88 \pm 0.28 \\
<0.01\end{array}$ \\
\hline \multicolumn{8}{|l|}{$15 \mathrm{~min}$} \\
\hline $\begin{array}{l}1 \text { SEM } \\
P\end{array}$ & $0.94 \pm 0.07$ & $\begin{array}{c}1.20 \pm 0.09 \\
<0.01\end{array}$ & $\begin{array}{c}1.47 \pm 0.19 \\
<0.01\end{array}$ & $\begin{array}{c}1.65 \pm 0.30 \\
<0.01\end{array}$ & $\begin{array}{c}1.95 \pm 0.23 \\
<0.01\end{array}$ & $\begin{array}{l}1.50 \pm 0.21 \\
<0.05\end{array}$ & $\begin{array}{c}1.08 \pm 0.07 \\
\text { NS }\end{array}$ \\
\hline \multicolumn{8}{|l|}{$4 \mathrm{~h}$} \\
\hline $\begin{array}{l}1 \text { SEM } \\
P\end{array}$ & $1.06 \pm 0.13$ & $\begin{array}{c}1.47 \pm 0.13 \\
<0.01\end{array}$ & $\begin{array}{c}1.48 \pm 0.16 \\
<0.01\end{array}$ & $\begin{array}{c}1.24 \pm 0.14 \\
\mathrm{NS}\end{array}$ & $\begin{array}{c}0.87 \pm 0.10 \\
<0.01\end{array}$ & $\begin{array}{c}0.58 \pm 0.11 \\
<0.01\end{array}$ & $\begin{array}{c}0.30 \pm 0.07 \\
<0.01\end{array}$ \\
\hline \multicolumn{8}{|l|}{3 days } \\
\hline $\begin{array}{l}1 \mathrm{SEM} \\
P\end{array}$ & $0.86 \pm 0.09$ & $\begin{array}{c}0.96 \pm 0.13 \\
<0.01\end{array}$ & $\begin{array}{c}1.05 \pm 0.13 \\
<0.01\end{array}$ & $\begin{array}{c}0.89 \pm 0.09 \\
\text { NS }\end{array}$ & $\begin{array}{l}0.77 \pm 0.09 \\
\quad<0.01\end{array}$ & $\begin{array}{c}0.46 \pm 0.07 \\
<0.01\end{array}$ & $\begin{array}{l}0.27 \pm 0.04 \\
\quad<0.01\end{array}$ \\
\hline
\end{tabular}

Myocardial blood flow in regions perfused by the left anterior descending and left circumflex coronary artery $15 \mathrm{~s}, 15 \mathrm{~min}$, $4 \mathrm{~h}$, and 3 days after release of a 2 -h complete occlusion of the circumflex coronary artery.

* Blood flows in left circumflex regions are grouped according to the percent of infarcted myocardium in each sample. Values are mean \pm SEM. $P$ values compare blood flow values in the regions containing infarcted myocardium to values in left anterior descending regions. NS, $P>0.05$.

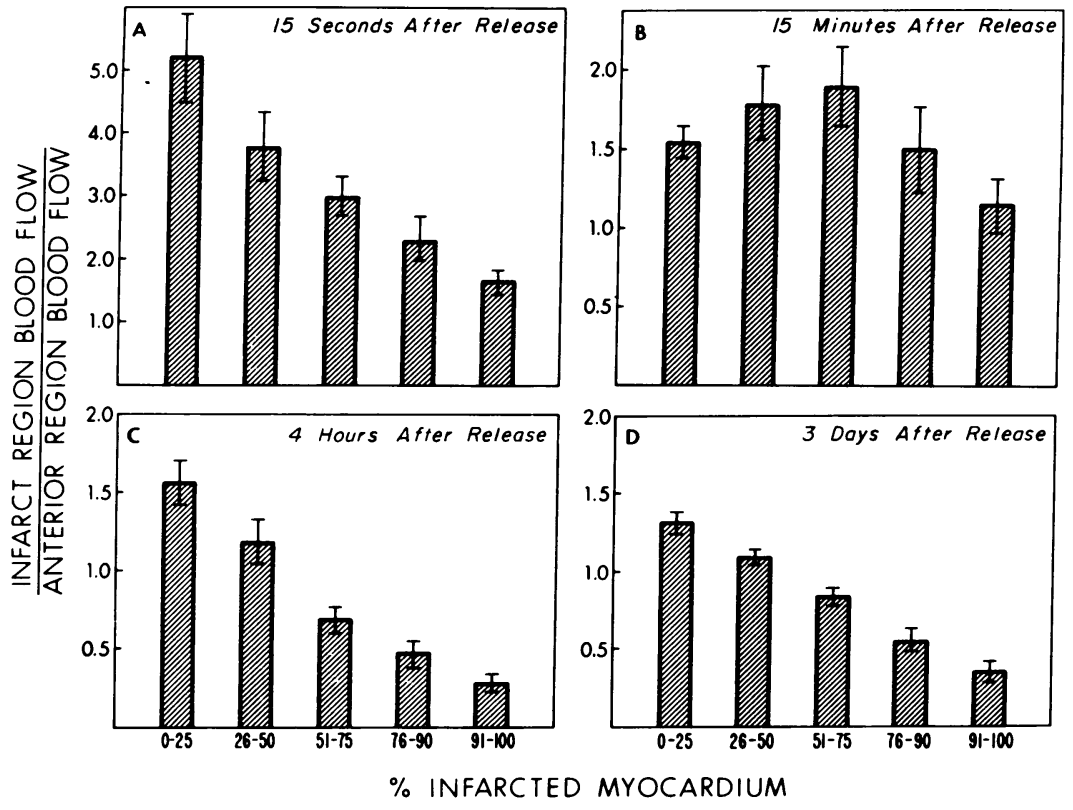

Figure 4 Myocardial blood flow responses $15 \mathrm{~s}$ (A), $15 \mathrm{~min}$ (B), $4 \mathrm{~h}$ (C), and 3 days (D) after release of a 2 -h occlusion are plotted as the ratio of blood flow in samples in the infarct region to flow in samples in comparable transmural layers from the anterior region. Ratios are plotted as a function of the percent of infarcted myocardium in each sample. Values are mean \pm SEM. 
parable to previous measurements of myocardial blood flow in awake trained animals (6).

Immediately after reperfusion of the region subjected to prolonged ischemia, blood flow was increased significantly, $P<0.01$, in myocardial samples in each infarct range (Fig. 4A). Although the net stimuli in each infarct range effected vasodilation, the hyperemic response was significantly different from that observed after brief ischemic stimulation of the normal myocardium and vasculature. Fig. 5 illustrates the blood flow response after the release of a $60-\mathrm{s}$ complete occlusion of the left circumflex coronary artery in a separate group of dogs which were not subjected to myocardial infarction. $10 \mathrm{~s}$ after release of a 60 -s circumflex coronary artery, occlusion blood flow was increased approximately fivefold in regions supplied by the transiently occluded coronary artery, the posterior, posterior papillary, and lateral regions (Fig. 5A). The transmural distribution of blood flow after release of the occlusion in these regions is illustrated in Fig. 5B. The distribution of blood flow was not significantly different in trans-

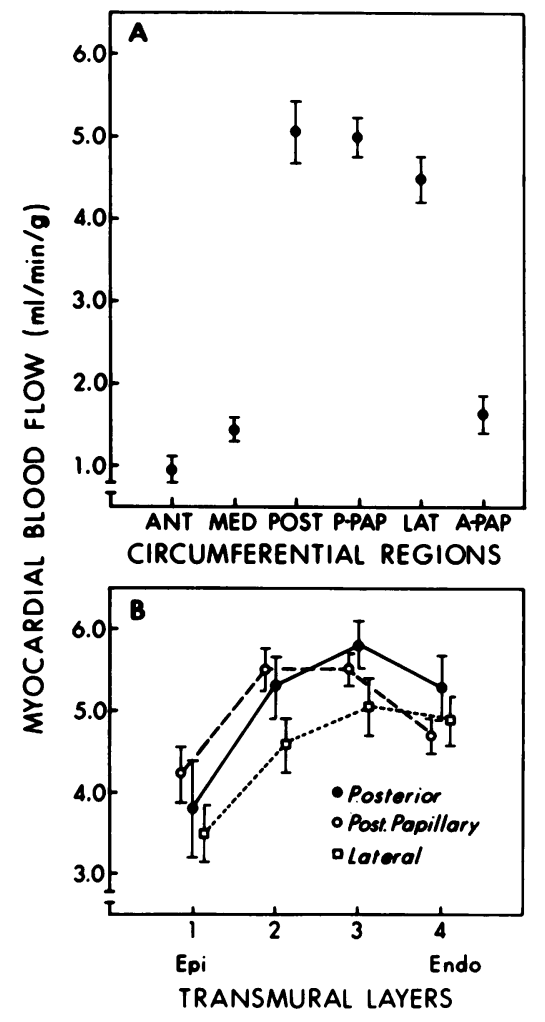

FIgURe 5 Myocardial blood flow in milliliters per minute per gram in circumferential regions of the left ventricle (A) and transmural layers from the posterior, posterior papillary, and lateral regions (B) measured after release of a 60 -s complete circumflex occlusion in eight dogs. Values are mean $\pm \mathrm{SEM}$. mural layers 2,3 , and 4 in each region. As compared to epicardial layer 1 , blood flow to layers 2,3 , and 4 was increased with the exception of blood flow to layer 4 in the posterior papillary muscle region, which was not significantly different from layer 1 . Thus, ischemic stimulation of the normal vasculature and myocardium effected marked vasodilation, resulting in a relatively even distribution of hyperemic blood flow in layers 2,3 , and 4 in each circumferential region of the ischemic zone. In contrast, prolonged ischemic stimulation sufficient to initiate subsequent cellular necrosis resulted in a hyperemic response which was not evenly distributed but was attenuated in direct proportion to the extent of subsequent cellular necrosis. The hyperemic response after prolonged ischemic stimulation as compared to brief ischemic stimulation was comparable only in samples which demonstrated $25 \%$ or less cellular necrosis.

15 min after reperfusion, myocardial blood flow remained increased in samples with $90 \%$ or less infarcted myocardium; however, the marked increments in blood flow observed immediately after reperfusion had decreased (Fig. 4B). As compared to flow values immediately after reperfusion, the greatest decrements in flow occurred in samples with the least infarction. Blood flow in samples containing $91-100 \%$ infarcted myocardium was slightly greater than flow in samples from comparable layers in the anterior region; however, the difference did not achieve statistical significance.

$4 \mathrm{~h}$ after reperfusion, blood flow in regions with greater than $25 \%$ infarcted myocardium had decreased as compared to blood flow values $15 \mathrm{~min}$ after reperfusion (Fig. 4C). Blood flow to samples with greater than $50 \%$ infarction was significantly decreased as compared to flow to anterior myocardial samples. Blood flow values were inversely related to the amount of subsequent cellular necrosis in each sample or directly related to the extent of subsequent intact myocardium.

3 days later, blood flow was increased in segments with $0-25 \%$ infarcted myocardium and decreased in segments with greater than $50 \%$ infarcted myocardium (Fig. 4D). As compared to blood flow $4 \mathrm{~h}$ after reperfusion, blood flow after 3 days of reperfusion was decreased in the anterior control region and in samples with $50 \%$ or less infarcted myocardium and was not significantly different in regions with greater than $50 \%$ myocardial infarction. Again, blood flow was inversely related to the extent of myocardial infarction or directly related to the extent of intact myocardium.

At 6 days postinfarction there was sharp delineation of intact and infarcted myocardium. The infarcted tissue contained a variable amount of hemorrhage which was greater in the more endocardial regions of the zone of infarction. The extent of myocardial infarction in each 
dog, determined by adding the infarct weight of each small tissue sample, ranged from 0.5 to $29.6 \mathrm{~g}$, mean infarct weight, $14.2 \mathrm{~g}$. The extent of infarction represented $0.4-27.5 \%$, mean $12.6 \%$, of the left ventricular weight.

\section{DISCUSSION}

The objective of the present study was to examine local effects of acute cellular injury on regional myocardial blood flow. Regional myocardial perfusion was measured at intervals after reestablishing flow to an area subjected to a period of ischemia sufficient to initiate acute myocardial infarction. Since blood flow was measured when inflow was not limited by proximal occlusion, the distribution of blood flow at intervals after reperfusion should reflect the net effect of ischemic vasodilation and the local effects of acute myocardial and (or) vascular injury on regional perfusion.

An area subjected to prolonged ischemia contains varying amounts of reversibly and irreversibly injured myocardium for a variable period of time after acute occlusion (7-10). The anatomic criteria for delineating irreversible from reversible cell injury early after ischemia remains controversial (11). Thus, in the present study, the extent of myocardial infarction was measured 6 days after coronary occlusion, so that intact and infarcted myocardium could be clearly delineated by routine histological sections. Although, as illustrated in Fig. 2, there is sharp separation between intact and infarcted myocardium at this point, the boundary between these tissues is irregular and characterized by intermingling of patches of intact and infarcted myocardium. Prolonged ischemia thus does not result in homogeneous infarction of the ischemic zone. Because of the heterogeneous nature of cellular necrosis, it was anticipated that selected histological samples from the ischemic zone may not accurately reflect the extent of infarction in each myocardial sample in which blood flow was measured. Thus, the relationship between regional myocardial perfusion and the extent of acute cellular injury was determined by measuring the blood flow in multiple small myocardial samples of the entire region subjected to prolonged ischemia, and then determining the extent of infarction in multiple sections of each sample.

In the present study, prolonged myocardial ischemia sufficient to initiate cellular necrosis effected local tissue responses, which altered regional perfusion at each interval analyzed after reperfusion. Blood flow responses immediately after release of the 2 -h occlusion assessed the net response to maximum ischemic stimulation, local accumulation or release of vasoactive by-products of cell injury, as well as direct effects of myocardial and vascular tissue injury. Prolonged ischemic stimulation suf- ficient to initiate cellular necrosis resulted in stimuli which effected vasodilation in each myocardial region. The hyperemic response was not evenly distributed in the area subjected to ischemia, but was inversely proportional to the extent of subsequent cellular necrosis or directly related to the extent of subsequent intact myocardium. In contrast, ischemic stimulation of the normal vasculature and myocardium for a brief duration sufficient to invoke maximum increases in blood flow resulted in an approximate fivefold increase in hyperemic flow, which was evenly distributed in layers 2,3 , and 4 . A comparable hyperemic response was observed after prolonged ischemic stimulation only in regions with $25 \%$ or less infarction. Thus, a small but significant degree of irreversible cell injury in a given myocardial sample did not alter the hyperemic response to ischemic stimulation, but greater cellular injury attenuated the response in proportion to the extent of subsequent myocardial infarction.

$15 \mathrm{~min}$ after reperfusion, vasoactive by-products which may have accumulated in the regions during the period of ischemia should have been removed. At this interval, the marked increments in the flow had decreased, but blood flow remained in excess or not significantly different from the flow to anterior regions. There was no clear relationship between blood flow and subsequent cellular necrosis. In the infarct ranges $0-5$, $6-25,26-50$, and $51-75 \%$ (Table I), mean blood flow values increased with each increment in percentage infarction, indicating continuing stimuli for vasodilation. Mean flow values in regions with $51-75,76-90$, and 91$100 \%$ infarction decreased with each increment in percentage infarction. Blood flow values at this interval may represent the interaction of vasoactive substances which continue to be released by the injured myocardium and tissue response which later reduced blood flow. Although at this interval, blood flow to areas which subsequently contained extensive infarction was not reduced below that to regions not subjected to ischemia, it is possible that flow was not adequate to meet the metabolic requirements of the injured tissue. The observation that flow to regions demonstrating less ischemic injury was higher than that to regions with greater injury support this view. Alternatively, the relative reduction in blood flow in the area of greater subsequent infarction may have been influenced by reduction in metabolic requirements as a consequence of irreversible cellular injury. The area subjected to ischemia undoubtedly contained varying amounts of normal and reversibly and irreversibly injured cells. Regional flow at this point may reflect the heterogeneous nature of the area subjected to prolonged ischemia.

$4 \mathrm{~h}$ and 3 days after reperfusion, blood flow was decreased below flow in the anterior control regions in 
samples with greater than $50 \%$ infarction. The decrements in flow were comparable at these intervals and were directly related to the extent of subsequent myocardial infarction. Although 3 days postinfarction blood flow was decreased in samples with greater than $50 \%$ infarction, significant blood flow remained even in samples with greater than $90 \%$ infarction. Blood flow in samples $0-5$ and $6-25 \%$ infarction was significantly increased. Blood flow at this point may represent the net response to residual intact myocardium and vasodilation resulting from the inflammatory reaction occurring throughout the infarcted region. Thus, in this model of infarction, maximum reduction in blood flow occurred within $4 \mathrm{~h}$ of reperfusion; acute cellular injury sufficient to initiate extensive infarction was required to reduce blood flow below that in regions not subjected to ischemic injury, and significant flow remained in regions of essentially complete infarction.

Prolonged ischemia initiated local tissue response which initially attenuated the hyperemic response and subsequently reduced blood flow in areas with extensive myocardial necrosis. Effects of acute cellular injury on tissue perfusion progressed after reperfusion and thus were a function of the time after reperfusion as well as the extent of subsequent cellular necrosis. These progressive effects of acute cellular injury on tissue perfusion may represent the normal tissue response to irreversible cellular injury and (or) abnormal response to reversible and, thus, potentially alterable, ischemic injury.

It is unlikely that differences in heart rate contributed significantly to the marked differences in blood flow observed at each interval. Blood flow to the anterior region which was not subjected to ischemia was not significantly different at $15 \mathrm{~s}, 15 \mathrm{~min}$, and $4 \mathrm{~h}$ despite a mean range of heart rates from 87 to 125 beats $/ \mathrm{min}$. Blood flow to the regions with greater than $50 \%$ infarction was not significantly different $4 \mathrm{~h}$ and 3 days after reperfusion, although the greatest difference in heart rate was observed between these intervals. 3 days after infarction, mean heart rate was 85 beats $/ \mathrm{min}$ and blood flow to the anterior nonischemic region was significantly lower than the preceding measurements and was similar to that measured in the normal myocardium of the resting dog (6). The lower blood flow response in the regions not subjected to ischemia and in the regions sustaining less than $50 \%$ infarction 3 days after infarction may represent the net effect of a lower level of basal sympathetic stimulation and lower heart rate.

In a recent study, Willerson et al. (5) compared regional blood flow measured $3 \mathrm{~min}$ after release of 10 - and 120-min complete coronary artery occlusions. Studies were carried out in dogs on right heart bypass. As compared to areas not subjected to ischemia, blood flow was increased in the ischemic region after both periods of ischemia. The increment in flow to the endocardial region after the $120-$ min occlusion, $1.5 \pm 0.42 \mathrm{ml} /$ min per $\mathrm{g}$, was significantly less than that after the 10 min occlusion, $2.28 \pm 0.25 \mathrm{ml} / \mathrm{min}$ per $\mathrm{g}$, indicating that prolonged ischemic stimulation reduced the hyperemia observed after $10 \mathrm{~min}$ of ischemia. Animals were sacrificed after the final blood flow measurement. The relationship between flow and extent of cellular necrosis was not examined.

Results of the present study and those of Willerson et al. (5) differ in certain respects from those of Kloner et al. (4). The latter investigators utilized thioflavin $S$, a fluorescent dye which stains endothelial cells to assess qualitatively blood flow to the posterior papillary muscle region $10 \mathrm{~s}$ to $20 \mathrm{~min}$ after release of $40-90-\mathrm{min}$ circumflex coronary artery occlusions. Studies were carried out in acute surgical preparations and animals were sacrificed after the injection of the fluorescent dye. The cellular injury in the areas subjected to ischemia was analyzed using light and electron microscopic techniques. Although both occlusions resulted in irreversible myocardial cell injury, fluorescence of the papillary muscle was not reduced after $40 \mathrm{~min}$ of ischemia but was reduced or absent in parts of the inner one-third of the papillary muscle region after $90 \mathrm{~min}$ of ischemia. In the present study, blood flow was increased in each region immediately after reperfusion and was increased or not significantly different from flow to areas not subjected to ischemia $15 \mathrm{~min}$ after reperfusion. Willerson et al. (5) also observed that blood flow to the area subjected to ischemia was increased $3 \mathrm{~min}$ after reperfusion as compared to flow in regions not subjected to ischemia. These differences may reflect differences in techniques for measuring flow and (or) differences related to the experimental models.

A variety of tissue responses resulting from prolonged ischemia have been implicated in the pathogenesis of altered tissue perfusion. It has been reported that prolonged ischemia of the kidney results in intracellular swelling of sufficient magnitude that capillaries are compressed and perfusion is decreased (12). Leaf (3) has hypothesized that such swelling may act as a self-perpetuating vicious cycle leading to cell death. Kloner et al. (13) observed that only modest myocardial cell swelling was present after $40 \mathrm{~min}$ of coronary occlusion, but that if the occlusion was released, myocardial cells in the ischemic region swelled as a result of a rapid increase in tissue water and electrolytes. The microvasculature did not appear to be damaged after this period of ischemia. In subsequent studies these investigators (4) observed that if the ischemic period was extended to $90 \mathrm{~min}$, myocardial cells were markedly swollen and there was focal swelling and disruption of capillary cells before reperfusion. Thioflavin $\mathrm{S}$ was used to assess blood flow after reperfusion after both periods of ischemia. 
As noted previously, reperfusion after 40 -min periods of occlusion was not associated with reduced areas of fluorescence. Reperfusion after 90 -min periods of occlusion was associated with reduced fluorescence in the endocardial region. Histological examination demonstrated myocardial cell injury in both the fluorescent and nonfluorescent areas but that capillary damage was limited to the latter area. It was concluded that reduced fluorescence resulted from extensive capillary damage which occurred after irreversible injury of myocardial cells. In the present study, blood flow was not reduced during the above interval after a 120 -min period of ischemia. It is possible that certain of the above cellular responses may have played a role in altering the hyperemic response after reperfusion and in the later reduction in flow observed in the present study.

Prolonged ischemia of the myocardium would be expected to alter severely the metabolic capabilities of cells within the ischemic zone. Rubio and Berne (14) presented evidence that formation and release of adenosine, a product of aerobic metabolism, mediates the close relationship between blood flow and myocardial metabolic activity. Prolonged ischemia could be expected to reduce the ability of the myocardial cells to synthesize vasodilator metabolites, which may link blood flow to myocardial metabolic needs. Consequently, blood flow to the acutely injured myocardium may be reduced disproportionate to metabolic requirements. In addition, as cell death occurs, any additional metabolic stimuli to flow ceases, resulting in reduced flow.

Certain investigators have concluded that the changes in perfusion resulting from prolonged ischemia may be altered. Grayson et al. (1), using anesthetized dogs, reported that coronary artery occlusion initiated coronary vasoconstriction which was mediated by local release of catecholamines and concluded that the vasoconstriction played a role in determining the extent of ischemic injury since adrenergic blockade increased blood flow to the ischemic region and reduced the extent of myocardial infarction. Other investigators have reported coronary vasoconstriction in response to ischemia (2), whereas others have found no evidence that blood flow to an ischemic region is increased by adrenergic blockade $(15,16)$. In a recent study, Willerson et al. (5) measured the regional blood flow response to hypertonic mannitol $3 \mathrm{~min}$ after release of an occlusion of 120-min duration. Mannitol increased blood flow in both the areas which were and were not subjected to ischemia. It was not determined whether the vasodilator response in the injured area also reduced the extent of cell injury.

Thus, prolonged ischemia may potentially initiate a variety of local tissue responses which directly alter perfusion of the injured myocardium. Whether a given response to prolonged ischemia also plays a role in de- termining the extent of subsequent cellular necrosis will depend on whether the response occurs before or after irreversible injury. The present study defines the relationship between blood flow and subsequent myocardial infarction and thus provides base-line data which can be utilized to elucidate further the local responses to ischemia which alter tissue perfusion, and to determine whether a given response plays a role in determining the extent of cellular injury.

\section{ACKNOWLEDGMENTS}

The authors wish to acknowledge the following individuals who rendered valuable assistance in carrying out this study: Dr. Donald B. Hackel for assistance with interpreting the histological sections; Dr. Philip A. McHale for assistance with the statistical analysis; Dr. Judith C. Rembert for assistance with the radioisotope measurements; Mr. Kirby Cooper, Mr. Eric Fields, Mr. James Ferrell, and Mr. Joe Gates for expert technical assistance; Mr. J. Michael Taylor and his staff of the Durham Veterans Administration Hospital Animal Care Facility; Mr. Donald G. Powell of the Durham Veterans Administration Hospital Medical Illustration Department; and Mrs. Rosa B. Ethridge and Mrs. Donna Silva for secretarial assistance.

This work supported in part by National Institutes of Health grants HL-18537 and HL-16438 from the U. S. Public Health Service. This was program number 1500-01 of the Veterans Administration.

\section{REFERENCES}

1. Grayson, J., M. Irvine, J. R. Parratt, and J. Cunningham. 1968. Vasospastic elements in myocardial infarction following coronary occlusion in the dog. Cardiovasc. Res. 2 : 54-62.

2. Hellstrom, H. R. 1971. Coronary artery stasis after induced myocardial infarction in the dog. Cardiovasc. Res. 5: 371-375.

3. Leaf, A. 1973. Cell swelling. A factor in ischemic tissue injury. Circulation. 48: 455-458.

4. Kloner, R. A., C. E. Ganote, and R. B. Jennings. 1974. The "no-reflow" phenomenon after temporary coronary occlusion in the dog. J. Clin. Invest. 54: 1496-1508.

5. Willerson, J. T., J. T. Watson, I. Hutton, G. H. Templeton, and D. E. Fixler. 1975. Reduced myocardial reflow and increased coronary vascular resistance following prolonged myocardial ischemia in the dog. Circ. Res. 36 : 771-781.

6. Cobb, F. R., R. J. Bache, and J. C. Greenfield, Jr. 1974. Regional myocardial blood flow in awake dogs. J. Clin. Invest. 53: 1618-1625.

7. Jennings, R. B., H. M. Sommers, G. A. Smyth, H. A. Flack, and H. Linn. 1960. Myocardial necrosis induced by temporary occlusion of a coronary artery in the dog. Arch. Pathol. 70: 68-78.

8. Cox, J. L., V. W. McLaughlin, N. C. Flowers, and L. G. Horan. 1968. The ischemic zone surrounding acute myocardial infarction. Its morphology as detected by dehydrogenase staining. Am. Heart J. 76: 650-659.

9. Maroko, P. R., J. K. Kjekshus, B. E. Sobel, T. Watanabe, J. W. Covell, J. Ross, Jr., and E. Braunwald. 1971. Factors influencing infarct size following experimental coronary artery occlusions. Circulation. 43: 6782.

Myocardial Infarction and Blood Flow 
10. Braunwald, E., and P. R. Maroko. 1974. The reduction of infarct size-an idea whose time (for testing) has come. Circulation. 50: 206-209.

11. Sobel, B. E. 1974. Biochemical and morphologic changes in infarcting myocardium. In The Myocardium: Failure and Infarction. E. Braunwald, editor. H. P. Publishing Co., Inc., New York. 247-260.

12. Flores, J., D. R. DiBona, C. H. Beck, and A. Leaf. 1972. The role of cell swelling in ischemic renal damage and the protective effect of hypertonic solute. J. Clin. Invest. 51: 118-126.

13. Kloner, R. A., C. E. Ganote, D. A. Whalen, Jr., and R. B. Jennings. 1974. Effect of transient period of ischemia on myocardial cells. II. Fine structure during the first few minutes of reflow. Am. J. Pathol. 74: 399413.

14. Rubio, R., and R. M. Berne. 1969. Release of adenosine by the normal myocardium in dogs and its relationship to the regulation of coronary resistance. Circ. Res. 25: $407-415$.

15. Redding, V. J., and J. R. Rees. 1968. Early changes in collateral flow following coronary artery ligation: The role of the sympathetic nervous system. Cardiovasc. Res. 2 : 219-225.

16. Kloner, R. A., K. A. Reimer, and R. B. Jennings. 1975. Distribution of local collateral flow after coronary occlusion in dogs: Effect of propranolol. Am. J. Pathol. 78: 33a-34a. (Abstr.) 